\title{
Coupling of remote sensing data and environmental-related parameters for dengue transmission risk assessment in Subang Jaya, Malaysia.
}

\begin{abstract}
In Malaysia, the endemic level of dengue fever (DF) has already changed morbidity indicators, and the magnitude of these incidences in the last few years has surpassed the incidences of all other diseases of compulsory notification. The reasons for the dramatic emergence of DF are complex and not well understood. There are many factors that contribute to the epidemiological conditions that favour viral transmission by the main mosquito vector. This study, therefore, is filling this gap by analysing the impact of dengue incidence at a local (Subang Jaya) scale using environmental factors. Meteorological data and land-use pattern were consolidated using geographic information system (GIS) and its components as an analytical tool. We have shown that weather variables (relative humidity, temperature and precipitation) have significant correlation with DF incidence with seasonal variation. Besides land-use pattern, DF incidence shows the higher distribution in the residential area, followed by commercial and industrial area. This is due to the higher population density in residential area as well as favourable places for the breeding of denguecarrying Aedes mosquitos created by humans in the residential area, especially one-storey houses. The analysis on the trends of DF incidence towards various housing types indicate that most of the victims' houses fall into interconnection houses and mixed houses types compared to the independent houses area. The outcome driven from this analysis suggested that each character of the environmental factors has their own risk towards dengue incidence. In line with that, it is possible to develop a dynamic model of DF transmission using the knowledge produced by this comprehensive time series data and the results provided by the different analyses.
\end{abstract}

Keyword: dengue fever (DF); risk assessment; geographic information system (GIS); remote sensing; Malaysia 